\title{
Adherence to American Society of Health-System Pharmacists Surgical Antibiotic Prophylaxis Guideline in Medical City Teaching
} Hospitals/Baghdad

* Ministry of health, Iraq.

\section{Nagham T. Salih ${ }^{* 1}$ and Dheyaa J. Kadhim ${ }^{* * *}$}

**Department of clinical pharmacy, College of Pharmacy, University of Baghdad, Baghdad, Iraq.

\section{Abstract}

Surgical site infections are the second most common type of adverse events occurring in hospitalized patients. Surgical antibiotic prophylaxis refers to the use of preoperative and postoperative antibiotics to decrease the incidence of postoperative wound infections. The objective of this study was to evaluate the antibiotic administration pattern for surgical antibiotic prophylaxis and the adherence to American Society of Health-System Pharmacists surgical antibiotic prophylaxis guideline in Medical City Teaching Hospitals/Baghdad. The medical records of one hundred patients who underwent elective surgical procedures were reviewed. Adherence to the recommendations of American society of health-system pharmacists guideline was assessed for every aspect of antibiotic prophylaxis.

The results of this study showed that antibiotic(s) had been administered to all of the patients involved in the study despite the fact that 34 patients $(34 \%)$ were not required such prophylaxis. While in case of administration time, 13 patients (13\%) had received the antibiotic(s) at correct time while 87 patients (87\%) at incorrect time. Proper antibiotic(s) selection was found in 11 patients $(11.0 \%)$ only. All of the patients $(100.0 \%)$ had received more than 2 doses, and all of them were not in concordance with surgical site infection prevention guidelines. In addition, 19 patients (19.0\%) with surgical site infections were identified during hospital stay or within 30 days after surgery.

According to these results, we can conclude that there was a substantial gap between surgical antibiotic prophylaxis guideline and their implementation in daily practice in Medical City Teaching Hospitals/Baghdad.

Keywords: Surgical Antibiotic Prophylaxis Guidelines, American Society of Health System Pharmacists guidelines, Medical City Teaching Hospitals/Baghdad.

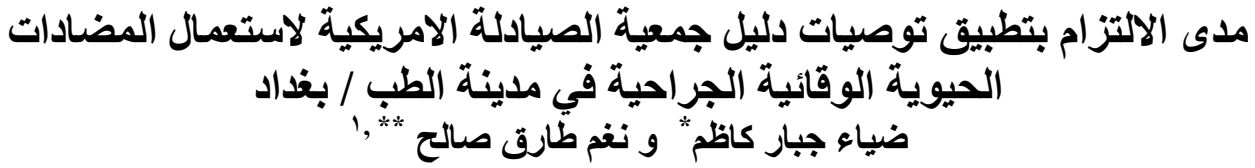

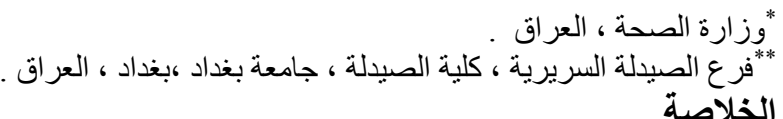

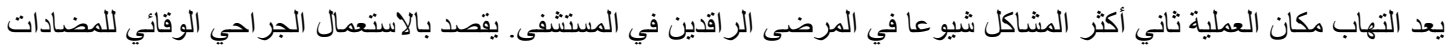

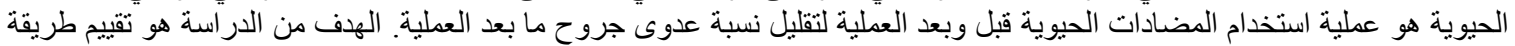

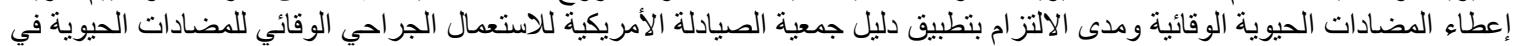

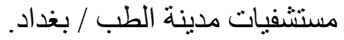

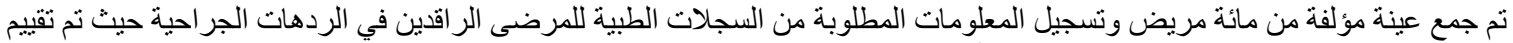

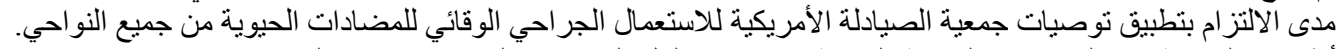

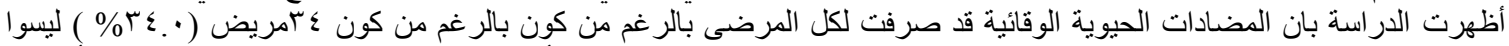

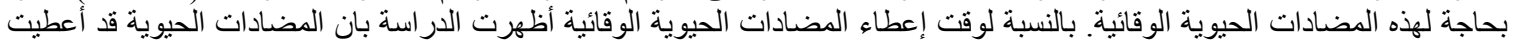

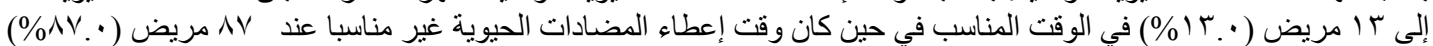

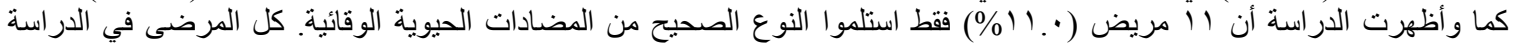

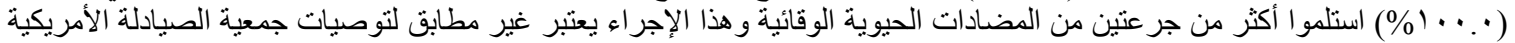

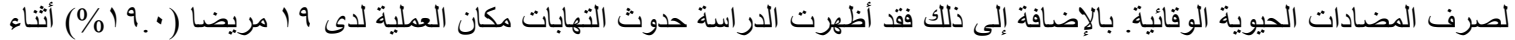

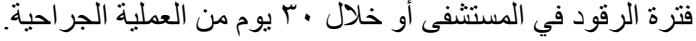

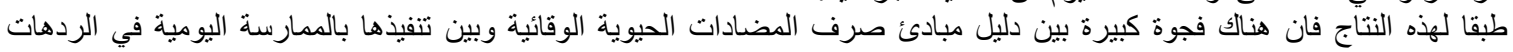

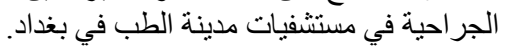
الكلمات المفتاحية: مضادات الحيوية الوقائية ، دليل جمعية الصيادلة الأمريكية ، مستثفيات مدينة الطب / بغداد.

${ }^{1}$ Corresponding author E-mail: naghamt.attar@gmail.com

Received: 8/ 8/ 2016

Accepted: 13 /12/2016 


\section{Introduction}

Surgical site infections (SSIs) are the commonest hospital-acquired infections in surgical patients ${ }^{(1)}$ and are the second most common cause of nosocomial infections ${ }^{(2)}$.They result in increased antibiotic usage, increased costs and prolonged hospitalization ${ }^{(1)}$. Surgical antibiotic prophylaxis may be defined as the appropriate use of preoperative and postoperative antibiotics to decrease the incidence of postoperative wound infections (3). Surgical operations are classified at the time of operation as clean, clean-contaminated, contaminated, or dirty. Dirty operations take place in situations of existing infection and antimicrobials are used for treatment, not prophylaxis ${ }^{(4)}$. Depending on best available evidence to optimize patient care and surgeon's practice, American Society of HealthSystem Pharmacists (ASHP) had developed a guideline for antimicrobial prophylaxis in surgery. According to this guideline: 1-Cefazolin (a first generation cephalosporin) is regarded the antimicrobial of choice for most surgical procedures. 2-The optimum administration's time for of prophylactic antibiotics dose is within 60 minutes before the surgical incision. 3Single-dose prophylaxis is usually sufficient with duration of less than 24 hours for all procedures. 4-Antimicrobial prophylaxis may be beneficial in surgical procedures associated with a high rate of infection (i.e., clean-contaminated or contaminated procedures) and in certain clean procedures where there are severe consequences of infection (e.g., prosthetic implants), even if Infection is unlikely ${ }^{(5)}$. Antibiotic administration continued beyond 24 hours has not been shown to be superior to shorter duration antibiotic prophylaxis in most surgical procedures. Singledose antibiotic prophylaxis provides the optimal balance for reducing wound infections in most operative procedures and decreasing adverse drug effects ${ }^{(3)}$.

This study aimed to evaluate an antibiotic administration pattern for surgical antibiotic prophylaxis in Medical City Teaching hospital (Baghdad) and to assess the adherence of practitioners to the guidelines for antimicrobial prophylaxis.

\section{Patients and Methods Patients}

The current study was carried out over two months from August - until October -2015 in general surgery wards in Baghdad Teaching Hospital and orthopedic surgery wards in Ghazi Al-Harriri hospital -medical city. One hundred patients [46 (46\%) male and 54(54\%) female] underwent elective surgeries with no preoperative infections were selected from general surgery and orthopedic surgery wards.

\section{Inclusion criteria}

Any patient undergoing elective surgery with no pre-operative infections and no antibiotic treatment prior hospital admission were included in the current study.

\section{Exclusion criteria}

Patients who received antibiotic(s) to treat infection were excluded since it was not possible to determine whether the antibiotic was given as treatment for the infection or as a surgical prophylaxis.

\section{Method}

The medical records of admitted patients who underwent different surgical procedures were reviewed during and the relevant information was entered on data collection form. The data including: Patients demographic information (age, gender, drug allergies ,past medical history, past surgical history, smoking ), type of surgical procedure( name of surgical procedure ,type of surgery ,class of surgery ), antibiotic therapy received (agent ,dose, initiation time duration of administration ), duration of surgical procedure, length of hospital stays, treatment on discharge and finally the presence of post-operative infection.

All study patients were followed up by phone calls contacted at home by telephone after 30 days or more post surgery. The patients were assessed about their general health and the state of the surgical according the following criteria (6):

1-Presence of fever.

2-Presence of erythema at wound site.

3-Presence of swelling, pain or heat at wound site.

4-Presence of discharge at wound site.

5-Have any antibiotic(s) been prescribed?

Compliance with the recommendations of ASHP guideline was assessed for every aspect of antibiotic prophylaxis ${ }^{(5)}$.

\section{Statistical analysis}

All data were coded, and SPSS version 22 (SPSS Inc., Chicago, Illinois, U.S.A) was used for the statistical analysis. The results were presented as mean \pm standard deviation and percent $(\%)$ where applicable. 


\section{Results}

The demographic, clinical and surgical characteristics of the patients are shown in table-1. Eighty three patients were collected from the general surgery ward and 17 patients from the orthopedic ward at Medical City Teaching Hospital-Baghdad. Concerning the type of surgery, $48 \%$ of surgical procedures were clean and $52 \%$ were clean-contaminated.

Table (1):- Demographic, clinical and surgical characteristics of the patients.

\begin{tabular}{|c|c|c|c|}
\hline \multicolumn{3}{|l|}{ Characteristics } & No. $(\%)$ \\
\hline \multirow[t]{2}{*}{ Gender } & \multicolumn{2}{|l|}{ Male } & $46(46 \%)$ \\
\hline & \multicolumn{2}{|l|}{ Female } & $54(54 \%)$ \\
\hline \multicolumn{3}{|l|}{ Age (years) } & $40.1 \pm 15.9$ \\
\hline \multirow[t]{2}{*}{ Smoking } & \multicolumn{2}{|l|}{ Yes } & $9(9 \%)$ \\
\hline & \multicolumn{2}{|l|}{ No } & $91(91 \%)$ \\
\hline \multirow[t]{2}{*}{ Drug allergy } & \multicolumn{2}{|l|}{ Yes } & $5(5 \%)$ \\
\hline & \multicolumn{2}{|l|}{ No } & $95(95 \%)$ \\
\hline \multirow[t]{2}{*}{ Surgical history } & \multicolumn{2}{|l|}{ Yes } & $71(71 \%)$ \\
\hline & \multicolumn{2}{|l|}{ No } & $29(29 \%)$ \\
\hline \multirow[t]{8}{*}{ Medical history } & \multicolumn{2}{|l|}{ No } & $74(74 \%)$ \\
\hline & \multicolumn{2}{|l|}{ Hypertension } & $11(11 \%)$ \\
\hline & \multicolumn{2}{|l|}{ Diabetes mellitus } & $7(7 \%)$ \\
\hline & \multicolumn{2}{|c|}{ Hypertension and Diabetes mellitus } & $4(4 \%)$ \\
\hline & \multicolumn{2}{|l|}{ Stroke } & $1(1 \%)$ \\
\hline & \multicolumn{2}{|l|}{ Thyrotoxicosis } & $1(1 \%)$ \\
\hline & \multicolumn{2}{|c|}{ Ischemic heart diseases } & $1(1 \%)$ \\
\hline & \multicolumn{2}{|l|}{ Hepatitis C } & $1(1 \%)$ \\
\hline \multirow[t]{4}{*}{ Surgical characteristics } & \multirow[t]{2}{*}{ Types of surgery } & General & $83(83 \%)$ \\
\hline & & Orthopedic & $17(17 \%)$ \\
\hline & \multirow[t]{2}{*}{ Surgical class } & Clean & $48(48 \%)$ \\
\hline & & $\begin{array}{l}\text { Clean- } \\
\text { Contaminated }\end{array}$ & $52(52 \%)$ \\
\hline
\end{tabular}

With respect to the appropriateness of antibiotic(s) administration according to patients' need, the study showed that antibiotic(s) had been administered to all of the patients involved in the study despite the fact that 34 patients (34\%) were not required such prophylaxis. Regarding the Appropriateness of antibiotic administration times, the current study showed that 13 patients $(13 \%)$ had received the antibiotic(s) at correct time (within 60 minutes of the first incision) while 87 patients $(87 \%)$ had received the antibiotic(s) at incorrect time [after surgery or more than 60 minutes of the first incision] as shown in table-2

Table (2):- Appropriateness of antibiotic(s) administration according to patients' need and antibiotic(s) administration time.

\begin{tabular}{|c|c|c|c|c|}
\hline \multirow{2}{*}{\multicolumn{2}{|c|}{$\begin{array}{l}\text { Requirement of antimicrobial } \\
\text { prophylaxis }\end{array}$}} & \multirow{3}{*}{$\begin{array}{c}\text { No. (\%). } \\
66(\%) \\
\end{array}$} & \multicolumn{2}{|c|}{ Appropriate time } \\
\hline & & & \multirow{2}{*}{$\frac{\text { Yes }}{9(9 \%)}$} & \multirow{2}{*}{$\frac{\text { No }}{57(57 \%)}$} \\
\hline Required & Administered & & & \\
\hline & Not administered & $0.0(\%)$ & $0.0(0.0 \%)$ & $0.0(0.0 \%)$ \\
\hline \multirow{2}{*}{$\begin{array}{l}\text { Not } \\
\text { Required }\end{array}$} & Administered & $34(\%)$ & $4(4 \%)$ & $30(30 \%)$ \\
\hline & Not administered & $0.0(\%)$ & $0.0(0.0 \%)$ & $0.0(0.0 \%)$ \\
\hline \multicolumn{2}{|c|}{ Total No. (\%). } & $100(100 \%)$ & $13(13 \%)$ & $87(87 \%)$ \\
\hline
\end{tabular}


Ceftriaxone -metronidazole combination was the most commonly prophylactic regimen used in the current study $(50.0 \%)$ followed by $(33.0 \%)$, cefotaxime $(6.0 \%)$, cefotaxime metronidazole combination $(5.0 \%)$, genamicin (2.0\%), ampicillin-cloxacillin combination $(2.0 \%)$, meropenem $(1.0 \%)$, and teicoplanin $(1.0 \%)$ (table-3). All of the patients $(100.0 \%)$ had received more than 2 doses and all of these $(100.0 \%)$ were not in concordance with surgical site infection prevention guidelines (table-4).

Table(3):- Antimicrobial(s) used for surgical prophylaxis.

\begin{tabular}{||l|l|l||}
\hline $\begin{array}{l}\text { Antibiotic for } \\
\text { prophylaxis }\end{array}$ & $\begin{array}{c}\text { Frequency } \\
\text { No. }(\%)\end{array}$ & $\begin{array}{c}\text { Rate of } \\
\text { concordance } \\
\text { with ASHP } \\
\text { guideline (\%) }\end{array}$ \\
\hline $\begin{array}{l}\text { Ceftriaxone - } \\
\text { metronidazole }\end{array}$ & $50(50.0 \%)$ & $7(7.0 \%)$ \\
\hline Ceftriaxone & 33 & $2(2.0 \%)$ \\
\hline Cefotaxime & $6(33.0 \%)$, & $0.0(0.0 \%)$ \\
\hline $\begin{array}{l}\text { Cefotaxime - } \\
\text { metronidazole }\end{array}$ & $5(5.0 \%)$, & $1(1.0 \%)$ \\
\hline Genamicin & $2(2.0 \%)$ & $1(1.0 \%)$ \\
\hline $\begin{array}{l}\text { Ampicillin- } \\
\text { cloxacillin }\end{array}$ & $2(2.0 \%)$ & $0.0(0.0 \%)$ \\
\hline Meropenem & $1(1.0 \%)$ & $0.0(0.0 \%)$ \\
\hline Teicoplanin & $1(1.0 \%)$ & $0.0(0.0 \%)$ \\
\hline \hline
\end{tabular}

ASHP: American Society of Health-System Pharmacists

Table (4):- Frequency of patients based on number of antibiotic(s) doses.

\begin{tabular}{||l|l|l||}
\hline \hline $\begin{array}{l}\text { Antibiotic } \\
\text { for } \\
\text { prophylaxis }\end{array}$ & $\begin{array}{l}\text { Frequency } \\
\text { No. (\%) }\end{array}$ & $\begin{array}{l}\text { Rate of } \\
\text { concordance } \\
\text { with ASHP } \\
\text { guideline } \\
(\%)\end{array}$ \\
\hline One dose & 0.0 & $(0.0 \%)$ \\
\hline Two doses & 0.0 & $(0.0 \%)$ \\
\hline $\begin{array}{l}\text { More than } \\
\text { 2 doses }\end{array}$ & $\begin{array}{l}\%) \\
\%)\end{array}$ & $(0.0 \%)$ \\
\hline
\end{tabular}

ASHP: American Society of Health-System Pharmacists

Regarding the rate of antibiotic(s) prescription at discharge, the results of the current study showed that antibiotics were prescribed to 96 patients $(96.0 \%)$ at discharge time, and only 4 patients $(4.0 \%)$ were discharged without antibiotic(s). Concerning the development of surgical site infections, nineteen patients $(19.0 \%)$ with surgical site infections were identified during hospital stay or within 30 days after surgery while no such infections were reported in 81 patients $(81.0 \%)$ (table-5). Finally overall assessment of appropriateness of prophylactic antibiotic administration in the 100 operations that included in the current study showed a complete lack of adherence to the guideline (table-6).

Table (5):-Development of surgical site infections.

\begin{tabular}{|l|l|}
\hline $\begin{array}{l}\text { Development of surgical site } \\
\text { infections }\end{array}$ & $\begin{array}{l}\text { Frequency } \\
\text { No. }(\%)\end{array}$ \\
\hline Yes & $19(19.0 \%)$ \\
\hline No & $81(81.0 \%)$ \\
\hline
\end{tabular}

Table (6):-Appropriateness of antibiotic prophylaxis regimen.

\begin{tabular}{||l|l||}
\hline \multicolumn{1}{|c||}{ Categories } & No. $(\%)$ \\
\hline Correct choice & $\begin{array}{l}11 \\
(11.0 \%)\end{array}$ \\
\hline $\begin{array}{l}\text { Correct choice + Correct } \\
\text { time }\end{array}$ & $\begin{array}{l}0.0 \\
(0.0 \%)\end{array}$ \\
\hline $\begin{array}{l}\text { Correct choice + Correct } \\
\text { time + Correct duration }\end{array}$ & $\begin{array}{l}0.0 \\
(0.0 \%)\end{array}$ \\
\hline
\end{tabular}

\section{Discussion}

The current study showed that antibiotic(s) had been administered to all of the patients involved in the study despite the fact that 34 patients $(34.0 \%)$ were not required such prophylaxis. In one study of 759 patients who underwent surgery, it was found that in about $10.0 \%$ of the surgeries included in the study, antimicrobial prophylaxis was given although it was not required according to according to the ASHP guideline ${ }^{(7)}$. Antibiotic prophylaxis may be beneficial in surgical procedures associated with a high rate of infection (cleancontaminated), while prophylactic antibiotics are not indicated for some clean surgical procedures (7). The three most important parameters of appropriateness of antibiotic prophylaxis which are antibiotic(s) choice, timing of administration of the first dose and the duration of prophylaxis were evaluated. Regarding timing of antibiotic prophylaxis, the current study showed that only $13 \%$ of the patients received prophylaxis at correct time and $87 \%$ of the patients received prophylaxis at incorrect time. Timing of prophylactic antibiotics administration is critical, with both early and late prophylactic antibiotics administration associated with increased SSI rates ${ }^{(8)}$.

In the current study only $11 \%$ of the patients received the appropriate antibiotic(s) recommended by the ASHP guideline. The first 
generation cephalosporin, cefazolin is regarded the antimicrobial of choice for most procedures according to ASHP guideline ${ }^{(5)}$. In this study, the combination of ceftriaxone-metronidazole was the most commonly used surgical prophylaxis regimen $(50 \%)$ followed by ceftriaxone alone which was administered to $33 \%$ of the patients. The use of third generation cephalosporins and aminoglycosides are not recommended for SSI prophylaxis because of less activity against staphylococci infection compared to cefazolin, and excessive use of broad spectrum antibiotics for prophylaxis increase the risk of resistance, causes more adverse events and increase health care cost ${ }^{(7)}$. Concerning the duration of surgical antibiotic prophylaxis, the current study showed that all of the patients $(100.0 \%)$ had received more than 2 doses and all of these $(100.0 \%)$ were not in concordance with surgical site infection prevention guidelines. The overuse of antibiotics was also demonstrated by the finding that antibiotics was prescribed to $96 \%$ of patients either as single agent or combination after discharge and only $4 \%$ of the patients discharged from hospital without antibiotics. Evidence is mounting that post-operative antimicrobial administration is not necessary for most procedures ${ }^{(5)}$. According to ASHP guideline, minimal duration for antimicrobial coverage includes the time from incision until the closure of that incision, which is usually covered by a single antibiotic dose ${ }^{(5)}$. The duration of antimicrobial prophylaxis should be less than $24 \mathrm{~h}$ for most procedures ${ }^{(2)}$. Overuse of antibiotic is not only an economic problem, but it place patients at risk for dangerous infections and exposure to unnecessary drugs and their harms (9). An Indian study reported that antibiotics were administered for as long as 14 days and only $1 \%$ to $8 \%$ of surgeons who prescribed antibiotic in surgical procedures stopped prophylaxis after 24hours ${ }^{(10)}$. Regarding the development of SSIs, the current study showed that SSIs were identified in 19 patients $(19.0 \%)$ during hospital stay or within 30 days after surgery while no such infections were reported in 81 patients $(81.0 \%)$. Post-discharge SSIs constitute the majority of SSIs and pose a substantial disease burden for surgical patients globally and for different surgery types ${ }^{(11)}$. In a study by Leaper et al., it was estimated that 30 million surgical procedures were conducted in Europe each year and rate of SSIs was (1.5-2.0 $\%)$ among them ${ }^{(12)}$. The higher rate of SSIs reported in the current study may be attributed to poor adherence to surgical prophylaxis guidelines. Finally, the current study showed that only $11.0 \%$ of the patients receive the correct choice of antibiotic and no one of the patients $(0.0 \%)$ received the antibiotic prophylaxis according to ASHP guidelines in regard to the main three parameters (choice, time, duration). In a 3-month period study of Surgical Hospital in Qatar, the compliance rate of antibiotic selection with the hospital infectious disease guidelines was $68.5 \%$, whereas compliance rate of antibiotic duration with hospital guidelines was $40.7 \%^{(13)}$.

\section{Conclusions}

Although evidence based guidelines exist to support the appropriateness of surgical antibiotic prophylaxis practices, there is a substantial gap between these guidelines and their implementation in daily practice in Medical City Teaching Hospital. Nonadherence to surgical prophylaxis guideline in Medical City Teaching hospital resulted in an increased rate of surgical site infections.

\section{References}

1. Wendy M. Antibiotic for surgical prophylaxis. Australian prescriber. 2005; 28 : 38-40.

2. Dale $\mathrm{WB}$ and Peter $\mathrm{MH}$. Antimicrobial prophylaxis for surgery: and advisory statement from national surgical infection prevention project. Clinical infectious disease. 2004; 38:1706 -1715.

3. Ronald LB, Surgical Infections and Antibiotic Prophylaxis. In David JQ, Richard AH. Textbook of Therapeutics: Drug and Disease Management. 8th edition. 2006. Pages: 2209 -2214.

4. Mary AU, John CR. Antimicrobial Prophylaxis in Surgery. In Chisholm-Burns, Barbara G.Wells, et al. Pharmacotherapy Principles \& Practice. 3rd edition. 2013. Pages: 1459-1467.

5. Dale WB, E. Patchen D, Keith MO, et al. Clinical practice guidelines for antimicrobial prophylaxis in surgery. Am J Health-Syst Pharm. 2013; 70:195-283 .

6. Piret M, Katrin H, Aira P, et al. Surgical-site infections following cesarean section in an Estonian university hospital: post discharge surveillance and analysis of risk factors. Infect Control Hosp Epidemiol. 2005; 26:449-454.

7. Mohammadreza R, Afshin sh, Amirhosein A, et al. Adherence to American society of health-system pharmacists surgical 
antibiotic prophylaxis guidelines in a teaching hospital. Journal of research in pharmacy practice. 2014; 3:62-66.

8. Apostolopoulou E, Zikos D, Georgoudi A, et al. The Impact of Irrational Perioperative Antibiotic Prophylaxis on the Nursing Workload. Health Science Journal. 2015; 9 (1:4): $1-5$.

9. Fridkin S, Baggs J, Fagan R, et al. Centers for Disease Control and Prevention (CDC). Vital signs: improving antibiotic use among hospitalized patients. Morb Mortal Wkly Rep. 2014;63:194-200.

10. R. A. Kulkarni, P. H. Kochhar, V. A. Dargude, et al. Patterns of antimicrobial use by surgeons in india. Indian $\mathbf{J}$ Surg. 2005;67:308-315.
11. Woelber E, Schrick E, Gessner B, et al. Proportion of Surgical Site Infections Occurring after Hospital Discharge: A Systematic Review. Surgical Infections. 2016; 17(5): 510-519.

12. David J.L, Harry V.G, Jacqueline R, et al. Surgical site infection - a European perspective of incidence and economic burden. International wound journal. 2004:1:247-273.

13. Abdel-Aziz A, El-Menar A, Al-Thani H,et al. Adherence of surgeons to antimicrobial prophylaxis guidelines in a tertiary general hospital in rapidly developing country. Advances in pharmacological sciences. 2013;2013:1-6. 